\title{
Being a COVID-19 Patient as an Infectious Diseases Physician
}

Mahir Kapmaz

Department of Infectious Diseases and Clinical Microbiology, Koç University Hospital, İstanbul, Turkey

This paper is dedicated to the memory of legendary clinician, Professor Cemil Taşçıoğlu who succumbed to COVID-19.

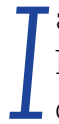
am an Infectious Diseases and Clinical Microbiology physician. We were at the frontline of the battle of COVID-19 soon after the first case in Turkey, that was officially L declared on 11 March 2020. Rick Penciner was a physician in Toronto during the SARS outbreak, and I was an intern when I read his text 'I am a SARS physician' (1). I all kept his advice on my mind, as the most significant one skipping the physical examination or not shaking the hands of the patients during that 'twilight zone'. Before COVID-19, I have to admit that I had no habit of wearing facemasks before the oropharyngeal examination of my patients. However, right after the alarm, we had strictly followed the directives and used personal protective equipment in our hospital.

\section{CASE}

Despite my adherence to the rules of infection control in my hospital, in the first days of the outbreak, I had a sudden onset of fever and chills with a headache on 25 March 2020. I had no catarrhal symptoms or myalgia. I am 41 years old with no chronic illnesses and never smoked cigarettes. My complete blood count (CBC) revealed a mild lymphopenia. The SARS-CoV-2 PCR (RealStar $®$, Altona Diagnostics, Germany) from initial nasopharengeal (NP) sample was negative. In day two, I had a computerized thorax tomography (CT) despite no respiratory symptoms. There was unilateral consolidation with central vascular enlargement, surrounded by ground-glass opacity (GGO) in the right middle lobe. The radiologists did not doubt that this lesion was consistent with COVID-19, and it was at least 5-7 days old. After seven days, I had an extra two NP PCR; all of them were negative. Multiplex respiratory PCR panel was negative. Urine Legionella antigen, and serum Mycoplasma and Chlamydia IgM were negative. Blood and urine cultures were negative. I received hydroxychloroquine for ten days, and azitromycin for the first four days. I had a continued fever between $37.2-38.3^{\circ} \mathrm{C}$. My inflammatory markers (LDH, CRP, d-dimer, ferritin, IL-6) were in normal ranges, but fever persisted. On day seven, I learned that Prof. Cemil Taşçıoğlu, the senior clinician of Istanbul University Faculty of Medicine, succumbed to COVID-19. On the same day, for that first time, I felt tightness on my chest. Follow-up chest X-ray on day eight, enlargement of the lesion was detected. I was given favipiravir because of persistent fever when it was available

\section{Corresponding Author: Mahir Kapmaz \\ E-mail: mahirkapmaz@yahoo.com}

Received: April 22, 20209 Accepted: April 29, 2020 Published: April 30, 2020

Suggested citation: Kapmaz M. Being a COVID-19 Patient as an Infectious Diseases Physician. Infect Dis Clin Microbiol 2020; 1: 48-51.

DOI: $10.36519 /$ idcm.2020.0008 
on day nine. The COVID-19 antibody rapid tests repeatedly done were negative.

I had a fever that lasted for 11 days with no accompanying signs! On day 19, serum IgG to SARS-CoV-2 (Acro Biotech $®$ Rapid Cassette, USA) turned to be positive. COVID-19 was reported to reveal three phases: viral, pneumonia and hyperinflammation phases (2). If so, which phase was compatible with my status?

a) If I was in the viral phase on the admission, then why were consequent NP PCRs negative?

b) If I was in the pneumonia phase, was the refractory fever a sign to be transferred to the intensive care unit (ICU)?

c) If I was in the hyperinflammation phase within eleven days, did I need some steroids?

\section{DISCUSSION}

I tried to focus on the clinical course of COVID-19. Most of the studies on COVID-19 have generally been limited to epidemiological information, initial clinical, haematological and radiological findings. Chen $J$ et al. saw this unmet need within the literature, and that they explored the temporal progression in patients with COVID-19. In their retrospective, single- centre study with 249 patients, the median age was 51 years old. The estimated median duration of fever was reported as ten days. It was 31 days in patients transferred to ICU vs nine days in whom did not $(p<0.0001)(3)$.

Wang Z et al. described clinical features of 69 cases with COVID-19 in Wuhan with the median age of 42. At the end of ten days of symptoms, 30 (43\%) patients had been reported to have a fever higher than $37.3^{\circ} \mathrm{C}$. Presence of fever was more frequent in hypoxic vs non-hypoxic group (4). My fever had also lasted almost eleven days. Fever lasting $>10$ days in COVID-19 seems to be a sign for poor prognosis. The duration of fever was reported as 11.4 days in SARS, eight days in MERS $(3,5,6)$.

Liu $\mathrm{K}$ et al. reported single lobe pulmonary lesion in $36.8 \%(14 / 38)$ of younger-middle age patients vs
$11.1 \%(2 / 18)$ in the elderly COVID-19 patients (7). In a systematic review of COVID-19 imaging findings including 919 patients by Salehi S et al., typical features of initial CT included bilateral, multilobar GGO with a peripheral or posterior distribution, mainly in the lower lobes, less frequently within the right middle lobe. They reported that consolidation superimposed on GGO as the initial presentation was found rarely, mainly in the elderly population. Nevertheless, this finding was consistent with my pulmonary lesion. CT within the intermediate stage of disease was reported to show progressive transformation of GGO into multifocal consolidations, septal thickening, and development of a crazy-paving pattern, with the greatest changes around day ten (8). My follow-up X-ray on day eight, revealing a mild progression of the lesion was consistent with this report, too.

Jin $\mathrm{YH}$ et al. described CT findings of COVID-19 in five temporal stages as ultra-early, early, rapid progression, consolidation, and dissipation stages (9). My initial presentation seemed to be consistent with the early, if not ultra-early, stage. My consequent negative results of NP PCR, however, was not compatible with this early stage. Chen $J$ et al. reported that the median time from onset of symptoms to PCR negative was 11 days in all the patients (3). As a comparison, it is 17 days in MERS $(3,6)$. In asymptomatic patients, PCR turned out to be negative two days after admission (3). Although I was not asymptomatic, an explanation for my negative PCR results was that my innate immunity was 'eager' enough to clear viral RNA from the upper respiratory system though it was not the situation for the alveolar system.

Chen J et al. reported the clinical progression of COVID-19 to show a biphasic pattern. The first clinical phase consisted of fever, cough and fatigue, and should include the ultra-early, early and rapid progression of radiological phases. They discuss that this progression could be explained by uncontrolled viral replication as presented with a positive SARS-CoV-2 PCR from their upper respiratory specimen. They claimed that as progression happens into week 2, COVID-19 patients enter the second phase while clearing the virus, and almost half had a normal temperature (3). Nevertheless, I thought 
that I was within this phase with a slight radiological progression although my PCRs were negative. As a comparison, the recurrence of fever and worsening of the patients two weeks later in SARS was reported (3).

Chen $J$ et al. discuss that failure in viral clearance observed in patients transferred to ICU is a common exception to this biphasic model. Persistent fever, lung damage and disease progression could be partially explained by uncontrolled viral replication and so-called hyperinflammation phase. They mention that an effective antiviral to early reduce the viral load may be crucial to reverse the poor course (3).

\section{What about if the symptoms last more than ten days?}

Mo $P$ et al. from Wuhan studied refractory COVID-19 pneumonia and tried to answer this question (10). In their retrospective single-centre study with 155 patients, the patients were divided into 70 general and 85 refractory cases. The median age was 46 vs 61. Nearly $50 \%$ of COVID-19 patients were reported not to reach clear clinical and radiological recovery within ten days after hospitalization. Those refractory patients had been reported to have a lower incidence of fever, higher levels of maximum temperature among fever cases, higher incidence of hypoxia, high levels of neutrophil, AST, LDH, and CRP, lower levels of platelets and albumin, and higher incidence of bilateral pneumonia and pleural effusion $(\mathrm{P}<0.05)$. They reported that these findings (especial- ly the absence of fever at admission) suggest that patients with a 'meagre' response to the virus were a candidate for severe disease (10).

Nevertheless, taking these results into account, I should find myself lucky that I skipped over this clinical stage. My laboratory findings were never abnormal despite the refractory fever. As a result, I do not think that I was able to find 'comprehensive' explanations for my disease course. However, a SARS-CoV-2 PCR analysis in my clinical samples of blood, urine, and especially stool would be more beneficial.

We, as Infectious Diseases Specialists, learned a lot from the viruses for the last 20 years.

i- We learnt from SARS that a virus can cause critical pneumonia by itself without addition of a secondary bacterial infection.

ii- We learnt the drug oseltamivir after pandemic H1N1 influenza A that it was waiting its turn for treatment of flu.

iii- Finally I think that, after the SARS-CoV-2 pandemic, physicians will never examine their patient's oropharynx without facemasks.

In conclusion, the unknown is much more than the known about COVID-19. There is a considerable need for further understanding of the natural disease course and relatedly the therapeutic approach.

\section{Acknowledgement}

I want to commemorate Professor Cemil Taşçığlu, who is the first healthcare worker victim of COVID-19 in Turkey. He was a legendary clinician at Istanbul University and taught each of his students how and why to perform a thorough physical examination for an accurate diagnosis. I revere the memory of him as a great teacher and clinical leader in medicine. I also thank Prof. Önder Ergönül, the chair of my department, and my colleagues, Associate Prof. Süda Tekin and Dr Pelin İrkören, for their contribution and their follow-up during my disease course.

Peer-review: Externally peer-reviewed

Conflict of Interest: The authors have no conflict of interest to declare.
Financial Disclosure: The authors declared that this study has received no financial support.

Statement: This paper is dedicated to the memory of legendary clinician, Professor Cemil Taşçıŏlu who succumbed to COVID-19. 


\section{REFERENCES}

1 Penciner R. I am a SARS physician. CJEM 2003; 5: 281-2

2 Siddiqi HK, Mehra MR. COVID-19 illness in native and immunosuppressed states: a clinical-therapeutic staging proposal. J Heart Lung Transplant 2020 Mar 20; doi:10.1016/j. healun.2020.03.012. [Epub ahead of print].

3 Chen J, Qi T, Liu L, Ling Y, Qian Z, Li T, et al. Clinical progression of patients with COVID-19 in Shanghai, China. J Infect 2020; 80: e1-e6.

4 Wang Z, Yang B, Li Q, Wen L, Zhang R. Clinical features of 69 cases with coronavirus disease 2019 in Wuhan, China. Clin Infect Dis 2020 Mar 16; ciaa272. doi:10.1093/cid/ciaa272. [Epub ahead of print].

5 Zhong NS, Zheng BJ, Li YM, Poon, Xie ZH, Chan KH, et al. Epidemiology and cause of severe acute respiratory syndrome (SARS) in Guangdong, people's re- public of China. Lancet 2003; 362:1353-8.

6 Choi WS, Kang CI, Kim Y, Choi JP, Joh JS, Shin HS, et al. Clinical presentation and outcomes of middle east respiratory syndrome in the republic of Korea. Infect Chemother 2016; 48 . 118-26.
7 Liu K, Chen Y, Lin R, Han K. Clinical feature of COVID-19 in elderly patients: a comparison with young and middle-aged patients. J Infect 2020 Mar 27. doi:10.1016/j.jinf.2020.03.005. [Epub ahead of print].

8 Salehi S, Abedi A, Balakrishnan S, Gholamrezanezhad A. Coronavirus disease 2019 (COVID-19): a systematic review of imaging findings in 919 patients. AJR Am J Roentgenol 2020 Mar 14;1-7. doi:10.2214/AJR.20.23034. [Epub ahead of print].

9 Jin YH, Cai L, Cheng ZS, Cheng H, Deng T, Fan YP, et al. Zhongnan Hospital of Wuhan University Novel Coronavirus Management and Research Team; Evidence-Based Medicine Chapter of China International Exchange and Promotive Association for Medical and Health Care (CPAM). A rapid advice guideline for the diagnosis and treatment of 2019 novel coronavirus (2019-nCoV) infected pneumonia (standard version). Mil Med Res 2020; 7: 4.

10 Mo P, Xing Y, Xiao Y, Deng L, Zhao Q, Wang H, et al. Clinical characteristics of refractory COVID-19 pneumonia in Wuhan, China. Clin Infect Dis 2020 Mar 16; ciaa270. doi:10.1093/cid/ ciaa270. [Epub ahead of print] 